\title{
Analysis of Feasibility of Peak Cooling Device Used with Direct Air Cooling Unit in Power Plant
}

\author{
Xing $\mathrm{CaO}^{1}$, Jinfeng Zhao ${ }^{1}$, Duanduan $\mathrm{Niu}^{2}{ }^{2}$, , Yan Jiang ${ }^{2}$ and Yingai $\mathrm{Jin}^{2}$ \\ 1 Jilin Province Electric Power Science Research Co Ltd, Changchun, Jilin, 130021, China \\ ${ }^{2}$ College of Automotive Engineering, Jilin University, Changchun, Jilin, 130022, China \\ aCorresponding author:1941708406@qq.com
}

Keywords: Direct air cooling unit, Evaporative condenser, Peak cooling device, Back pressure, Ash deposition.

\begin{abstract}
In order to reduce the back pressure of direct air cooling unit and increase power output of steam turbine in summer, the cold end system of a power plant is optimized through adding evaporative condenser as peak cooling device. Through experiments, this artical compares the effect on back pressure in the case of inputting the peak cooling device and cutting off peak cooling device with different load and different temperature in summer, also the effect of ash deposition on exhaust pressure is studied. The results show that the unit in different load of 500WM, 400WM, 380WM, 300WM and different temperature of $29^{\circ} \mathrm{C}, 33^{\circ} \mathrm{C}, 30^{\circ} \mathrm{C}, 27^{\circ} \mathrm{C}$ respectively, when putting into the peak cooling device, back pressure reduces $22 \mathrm{kPa}, 13.1 \mathrm{kPa}, 10.8 \mathrm{kPa}, 6.7 \mathrm{kPa}$ respectively; when cutting off the peak cooling device, the back pressure increases $27 \mathrm{kPa}, 14 \mathrm{kPa}, 11.4 \mathrm{kPa}$ and $5.4 \mathrm{kPa}$ respectively. The ash deposition can increase the back pressure. The back pressure has been reduced about $9 \mathrm{kPa}$ after cleaning ash deposition when cutting off the peak cooling device.
\end{abstract}

\section{Introduction}

In order to reduce the back pressure of direct air cooling unit and increase power output of steam turbine in summer, most direct air cooling units have been used peak cooling device. Douglas analyzed the back pressure of evaporative condenser system was lower than water cooling system and air cooling system[1]. American Tradewinds company's sawmill power generation system and Canada's Trans Alta energy company's combined power generation system use the evaporative condenser, and the application effect is significant[2]. FAN Xiao-chao introduce peak load spray humidification changed in Datang Binchang power generation Co.Ltd, solved the problem of high back pressure and limited load[3]. Professor Zhu Dongsheng's team developed vertical and plate shell evaporative condensers for power plants[4]. This paper analyzes the actual operation of a power plant in Jilin Province, used the evaporative condenser to improve the heat dissipation capability of the exhaust end. The experimental data have a good reference value for the combined operation of direct cooling and peak cooling in domestic power plants.

\section{Arrangement And Working Principle Of Peak Cooling Device}

\subsection{Arrangement of Peak Cooling Device}

The air cooling system is equipped with a peak cooling device which operates in parallel with the direct air cooling systeml, the unit uses evaporative condenser as peak cooling device, the process is as follows: The exhaust pipe is added from the existing exhaust pipe of turbine into the evaporative condenser, the exhaust pipe is provided with expansion joints and electric butterfly valve. When back pressure is high, open the electric butterfly valve so that part of the steam flow to the serpentine coil of evaporative condenser. Cooling water through the water supply system evenly sprayed on the serpentine coil, utilized the latent heat of cooling water to condense the steam turbine. After cooled, the condensed water is returned to the exhaust device and mixed with the condensed water by direct air condenser , enter the main condenser water system finally. When back pressure is low, close the valve, so that all the 
exhaust through the direct air cooled unit to condense. Combined operation diagram of air-cooled condenser and evaporative condenser is shown in Fig.1.

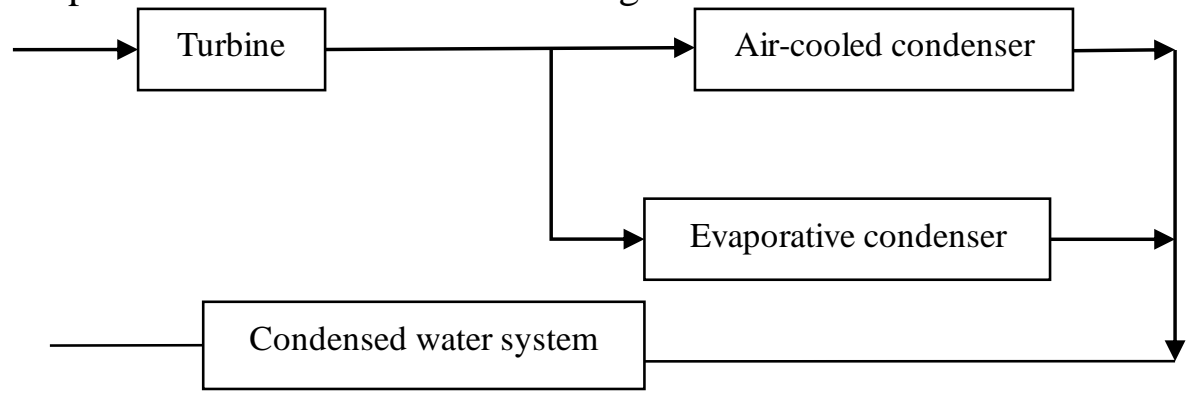

Figure 1. Combined operation diagram of air-cooled condenser and evaporative condenser

\subsection{The working principle of evaporative condenser}

The cold end system of a power plant is optimized and transformed, and added the evaporative condenser of peak cooling device. The exhaust steam of turbine is condensed into the evaporative condenser, condensed water flows into the condensed water tank, and non-condensable gas is discharged by the evacuated tube. When condensation of the inner pipe steam will emit heat, the heat of the tube to spray water evaporate. The non-evaporated water flows into the lower water tank and is pumped to the upper part of the heat transfer module through the water pump. After the nozzle is sprayed, the water film layer is formed along the surface of the heat exchanger module to realize the circulation of the spray water. The nozzle is equipped with a water collector, to avoid the water droplets are taken away. The evaporative condenser mainly uses the latent heat of water evaporation, the heat exchange mechanism is advanced and efficient, and the effect of heat transfer depends on the local wet bulb temperature. Condensation temperature (back pressure) is low, due to the evaporation of water latent heat, less water can meet the demand of heat exchange, the device is highly efficient, with less freight and a lower investment.

\section{Performance Test of Peak Cooling Device}

Under the condition of different load and different temperature, rated fan speed, inputting and cutting off peak cooling device on the unit to test. Basic parameters of power plant unit are shown in table 1:

Table 1 Basic parameters

\begin{tabular}{|c|c|c|}
\hline Main Parameters & Unit of Parameter & Data \\
\hline Power output of unit & MW & 660 \\
\hline Main steam pressure & $\mathrm{MPa}$ & 24.2 \\
\hline Reheat steam pressure & $\mathrm{MPa}$ & 3.65 \\
\hline High pressure cylinder exhaust pressure & $\mathrm{MPa}$ & 4.05 \\
\hline Back pressure & $\mathrm{kPa}$ & 10 \\
\hline Exhaust flow of Low pressure cylinder & $\mathrm{t} / \mathrm{h}$ & 1209.21 \\
\hline
\end{tabular}

Unit power and ambient temperature : 500WM-29 ${ }^{\circ} \mathrm{C}, 400 \mathrm{WM}-33{ }^{\circ} \mathrm{C}, 380 \mathrm{WM}-30{ }^{\circ} \mathrm{C}$, $300 \mathrm{WM}-27^{\circ} \mathrm{C}$. The test data is recorded every 30 seconds.

Figure 2 shows change curve of unit back pressure after inputting and cutting the peak cooling device during 300WM $27^{\circ} \mathrm{C}$. The test time is 20: 00-21: 00,19: 30-19: 50 of the day. It can be seen from the figure that the back pressure of the unit started to decrease rapidly after operating 5 minutes of peak cooling device, and the back pressure began to stabilize from $30.2 \mathrm{kPa}$ to $13.9 \mathrm{kPa}$ after operating 30 minutes and the back pressure droped by $6.7 \mathrm{kPa}$ and decreased by $33.2 \%$. After the peak cooling device was removed, the unit back pressure started to rise sharply and stabilized eventually, rised from $15.3 \mathrm{KPa}$ to $20.7 \mathrm{kPa}$, and the back pressure increased by $5.4 \mathrm{kPa}$ and increased by $26.1 \%$ in $20 \mathrm{~min}$.

Figure 3 shows change curve of unit back pressure after inputting and cutting the peak cooling device during $380 \mathrm{WM} 30^{\circ} \mathrm{C}$. The test time is $12: 25-13: 30,11: 30-11: 50$ of the day. It can be seen from the figure that the back pressure started to decrease rapidly after operating peak cooling device, and the back pressure began to stabilize from $27.3 \mathrm{kPa}$ to $16.5 \mathrm{kPa}$ and the back pressure droped by $10.8 \mathrm{kPa}$ and 
decreased by $39.6 \%$. After the peak cooling device was removed, the unit back pressure started to rise from $17.1 \mathrm{kPa}$ to $28.5 \mathrm{kPa}$, and the back pressure increased by $11.4 \mathrm{kPa}$ and increased by $66.7 \%$.

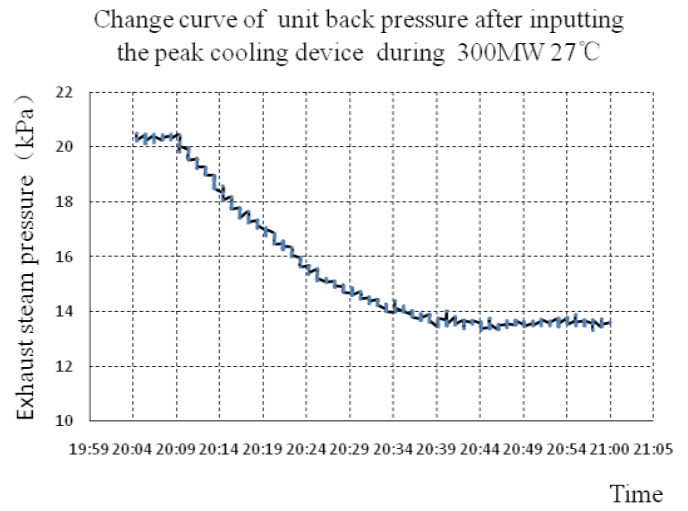

Change curve of unit back pressure after cutting the peak cooling device during $300 \mathrm{MW} 27^{\circ} \mathrm{C}$

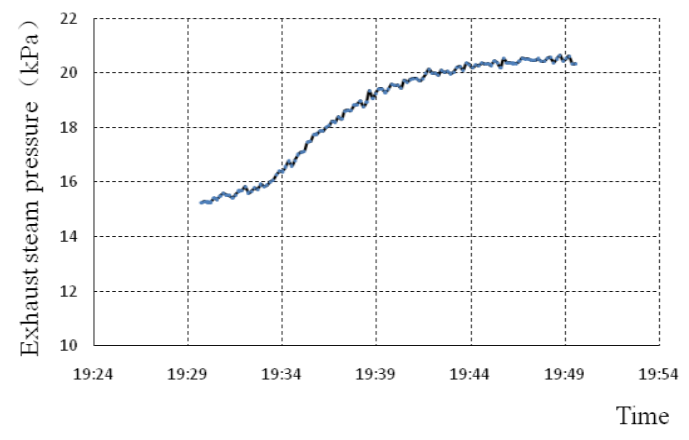

Figure2. Change curve of unit back pressure after inputting and cutting the spike cooling device during $300 \mathrm{WM} 27^{\circ} \mathrm{C}$
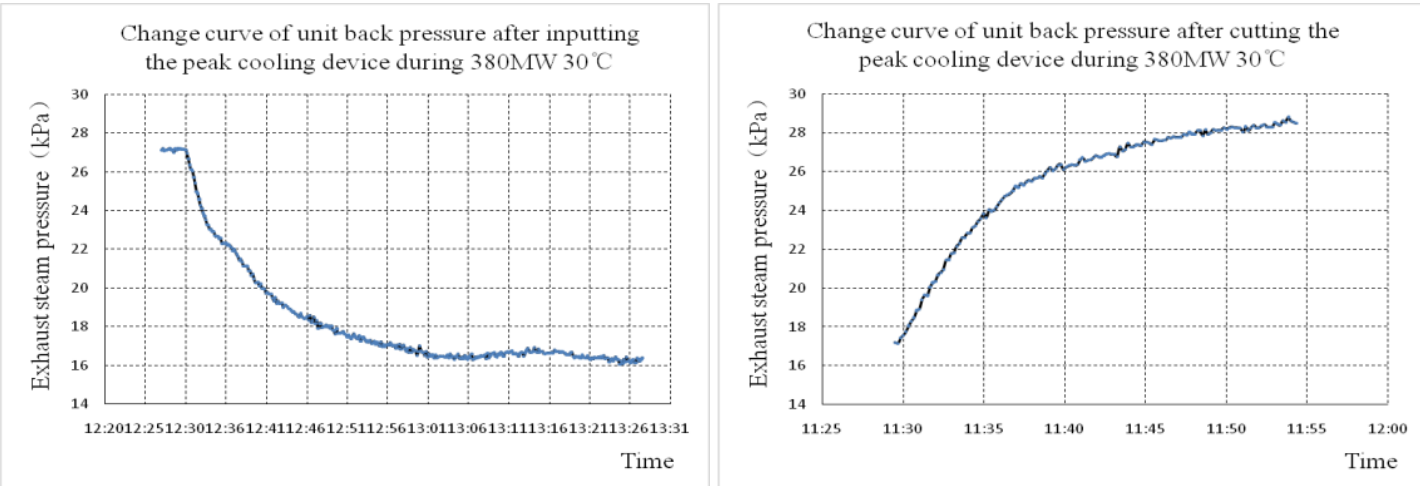

Figure3. Change curve of unit back pressure after inputting and cutting the spike cooling device during $380 \mathrm{WM} 30^{\circ} \mathrm{C}$
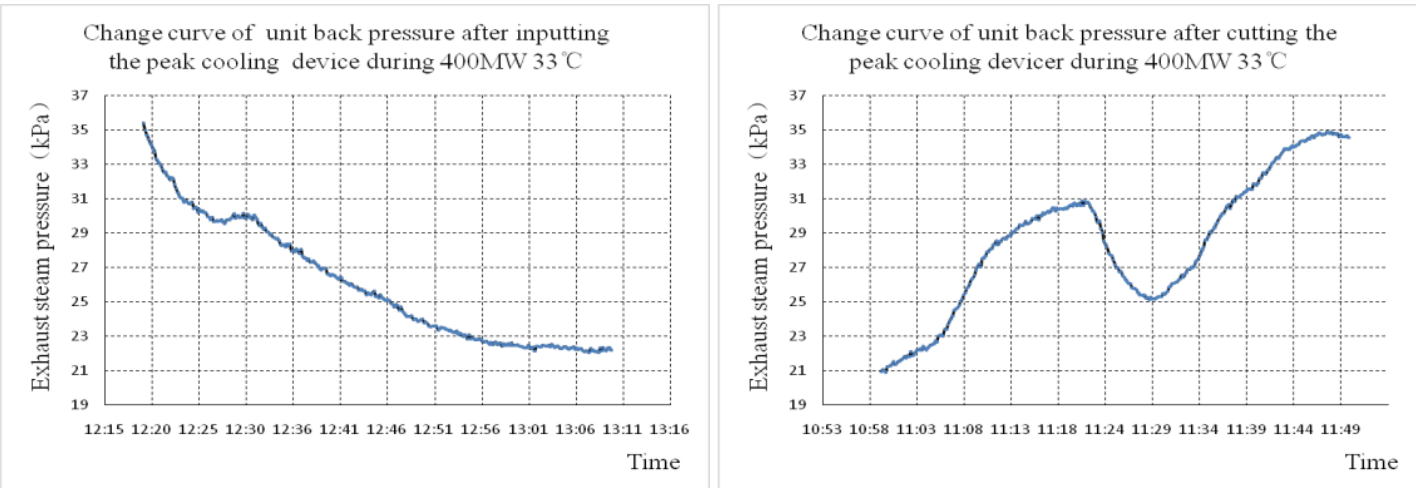

Figure4. Change curve of unit back pressure after inputting and cutting the peak cooling device during $400 \mathrm{WM} 33^{\circ} \mathrm{C}$

Figure 4 shows Change curve of unit back pressure after inputting and cutting the peak cooling device during $400 \mathrm{WM} 33^{\circ} \mathrm{C}$. The test time is 12:15,-13:10, 11:00-11:50 of the day. It can be seen from the figure that the back pressure of the unit starts to decrease rapidly after operating the peak cooling device, and the back pressure begins to stabilize from $35.4 \mathrm{kPa}$ to $22.2 \mathrm{kPa}$ after operating 39 minutes and the back pressure drops by $13.2 \mathrm{kPa}$ and decreased by $37.3 \%$. After the peak cooling device was removed, the unit back pressure started to rise sharply and middle beating constantly, rising from $21 \mathrm{kPa}$ to $34.8 \mathrm{kPa}$, and the back pressure increased by $13.8 \mathrm{kPa}$ and increased by $39.66 \%$. 

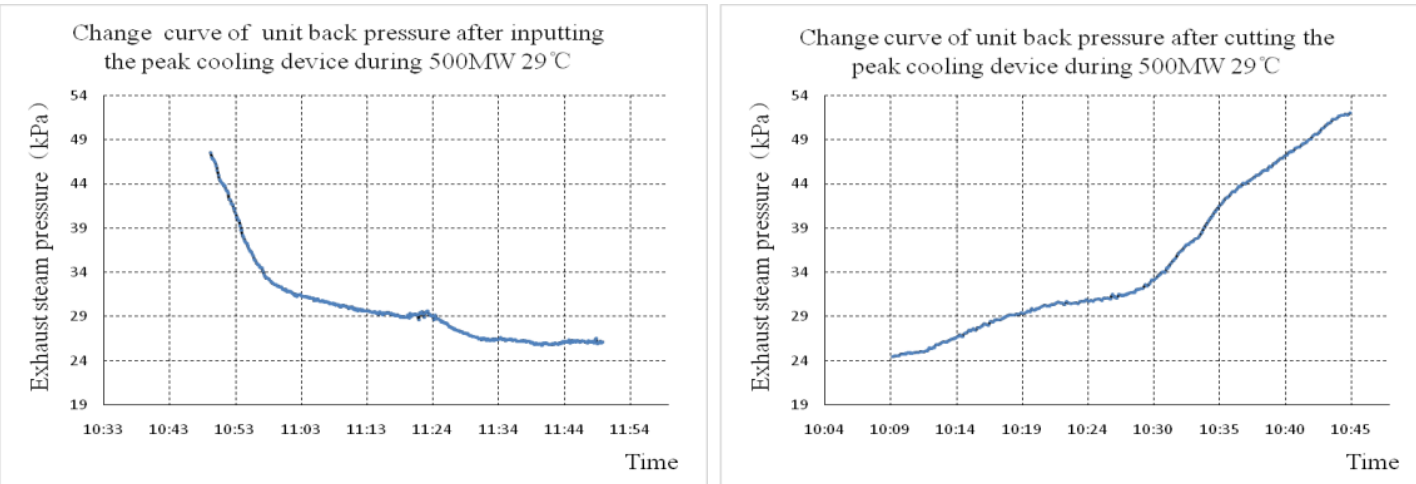

Figure5. Change curve of unit back pressure after inputting and cutting the peak cooling device during $500 \mathrm{WM} 29^{\circ} \mathrm{C}$

Figure 5 shows Change curve of unit back pressure after inputting and cutting the peak cooling device during 500WM $29^{\circ} \mathrm{C}$. The test time is 10:50-11:50, 10:00-11:40 of the day. It can be seen from the figure that the back pressure starts to decrease rapidly after operating peak cooling device, and the back pressure begins to stabilize from $47.8 \mathrm{kPa}$ to $26.2 \mathrm{kPa}$ and the back pressure drops by $21.6 \mathrm{kPa}$ and decreased by $45.2 \%$. After the peak cooling device was removed, the unit back pressure started to rise from $24.5 \mathrm{kPa}$ to $52.6 \mathrm{kPa}$, and the back pressure increased by $26.1 \mathrm{kPa}$ and increased by $49.62 \%$.

In the case of little change of ambient temperature, in the high-load operation, the back pressure can be reduced by about $10 \mathrm{kPa}$, the effect of operating peak cooling device is good. However, in the low-load operation, the effect is poor relatively.

\section{Effect Of Ash Deposition On Exhaust Pressure}

In order to strengthen the air side of the heat transfer process, the finned tube is adopted in the direct air condenser, the fin arrangement is compact and the fin spacing is small. In the summer, with the increase of the ash thickness, the heat transfer performance deteriorates, which leads to the decrease of the heat transfer coefficient, the reduction of the radiator efficiency, and the raise of the condenser pressure continuously.
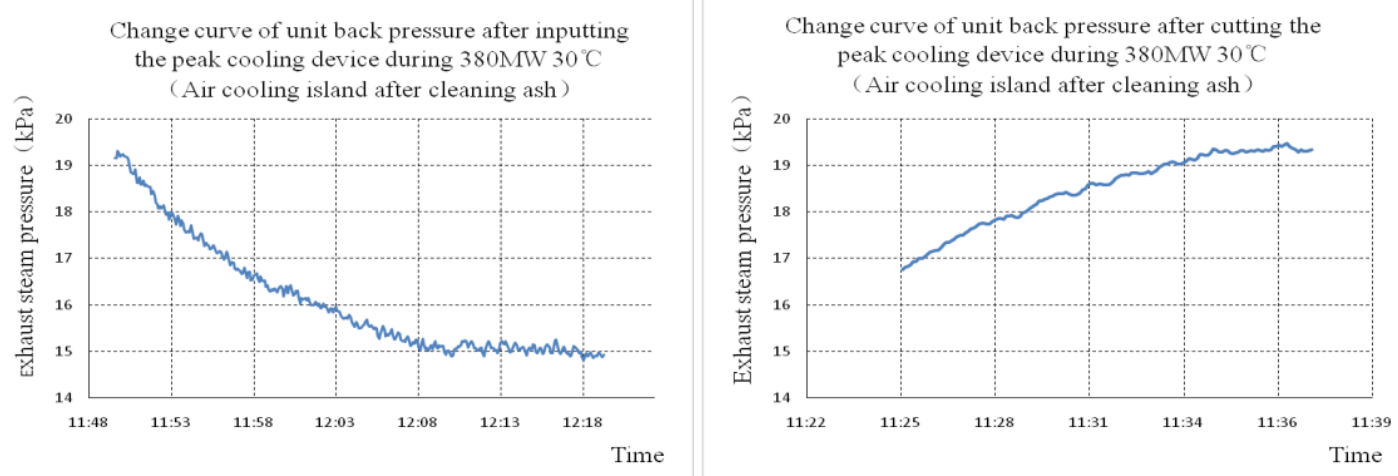

Figure6. Change curve of unit back pressure after inputting and cutting the peak cooling device during $380 \mathrm{WM} 30^{\circ} \mathrm{C}$ (Air cooling island after cleaning ash)

Figure 6 shows the experimental study of air cooling island after cleaning ash during $500 \mathrm{WM} 29^{\circ} \mathrm{C}$. The test time is 10: 50-11: 50, 10: 00-10: 40 of the day. It can be seen from the figure that the back pressure started to decrease rapidly after operating peak cooling device, and the back pressure begian to stabilize from $19.3 \mathrm{kPa}$ to $14.8 \mathrm{kPa}$ and the back pressure droped by $4.5 \mathrm{kPa}$ and decreased by $23.32 \%$. After the peak cooling device was removed, the unit back pressure started to rise from $16.7 \mathrm{kPa}$ to $19.3 \mathrm{kPa}$, and the back pressure increased by $2.6 \mathrm{kPa}$ and increased by $15.57 \%$.

It can be seen from Figure 6, after the air-cooled island cleaning, putting the peak device, the exhaust pressure reduced to $15 \mathrm{kPa}$, the exhaust pressure before cleaning ash reduced to $16 \mathrm{kPa}$; After the peak cooling device was removed, the exhaust pressure rose sharply, and finally stabilized at about $19.3 \mathrm{kPa}$. 
The exhaust pressure before cleaning ash reduced to $28.5 \mathrm{kPa}$, difference between two about $9 \mathrm{kPa}$. It can be seen that existence of ash will increase the back pressure.

\section{Conclusion}

This paper states on the feasibility of peak cooling device which is used in a direct air cooling unit. We are contrast and analysis the changes of back pressure after inputting and cutting off peak cooling device in summer. The conclusions as follows:

1. In order to reduce the back pressure of direct air cooling unit in summer, the peak cooling device is used with the direct air cooling unit in the power plant, putting the peak device reduces back pressure significantly, improves economy and security of the unit.

2. The efficiency of the peak cooling device is affected by ambient temperature and load. When the load is more than $380 \mathrm{MW}$, and the exhaust pressure can be reduced by an average of $10 \mathrm{kPa}$ when peak cooling device is in use. The more the load increases, the more exhaust pressure decreases.

3. For power plants which have been put into direct air cooling unit, in order to reduce the back pressure of direct air cooling unit and increase power output of steam turbine in summer, it is necessary to use the peak cooling device to increase the heat dissipation capability of the exhaust end.

4. The existence of ash on the tube bundle of the air-cooled unit will decrease the heat transfer performance of the condenser and cause back pressure to rise. Heat transfer performance is improved and the back pressure is reduced after cleaning up the ash,.

\section{Acknowledgements}

The programme [Improving the Combustion Mode and Security Running Control Strategy to Decrease the Pollution in Northeast of China( UK-CIAPP1201) ] was supported by the Royal Academy of Engineering under the UK-China Industry Academia Partnership Programme scheme. The authors are grateful for the support of the Royal Academy of Engineering and the UK government's Newton Fund. This work was also supported by project "Study on cold junction optimization of the parallel operation system of air cooled condenser and peak heat exchanger and the heat transfer characteristics of the system, No.: KY-GS-17-01-06" .

\section{References}

[1]. Hutton, David. Improved Power Plant Performance with Evaporative Steam Condensing [J]. CTI Journal, 1999, 20(1):34 58

[2]. Douglas Smith. Power Plant Cooling Systems: The Unsung Heroes [J]. Power Engineering, 2001, 105(5): 55 62.

[3]. Xiaochao Fan, Yue Dang, Jinglin Shi, et al.The Change and Performance Analysis of Peak Load Cooling SystemUsed in 600MW Direct Air Cooling Unit[J].Turbine Technology, 2013, 55(4):300-302.

[4]. Changqing Guo, Dongsheng Zhu, Changfeng Yan. Research Progress and Application of Evaporative Condenser in Power Generation System[J].Power System Engineering, 2010, 06: 27-30.

[5]. Chunyan Wang, Weikang Zhang, Ming Sun, et al.Optimization of cold end system on 660MW supercritical direct air cooling unit[J].Jilin Electric Power, 2016, 44(2):49-51.

[6]. Shengjiang Guo, Guobang Chen, Xingjie Dong. Feasibility analysis of the application of evaporative condensers to cooling system in thermal power plant[J].Zhejiang Electric power, 2004, 23(4):53-57. 
[7]. Defei Ren, "Research on the operation regulation of dust accumulation on air-cooled condenser," Ph.D. thesis, North China Electric Power University (Beijing) North China Electric Power University, 2011. 